\title{
LAS ÁREAS DE ACTIVIDAD EN LA UNIDAD RESIDENCIAL PREHISPÁNICA: PROPUESTA DE CONCEPTUALIZACIÓN PARA SU CLASIFICACIÓN, MÁS ALLÁ DE "LO DOMÉSTICO"
}

\author{
ARTURO JUAN NOEL ESPINOZA* \\ Universidad Nacional Mayor de San Marcos \\ anoel1212@yahoo.es
}

\section{RESUMEN}

Se presenta una propuesta teórica-metodológica para la conceptualización de unidades de clasificación referidas a las áreas de actividad que puedan identificarse en asociación a unidades residenciales prehispánicas de los Andes Centrales ${ }^{1}$, como resultado del análisis formal y funcional de un muestreo representativo de reportes arqueológicos.

La definición conceptual de la unidad residencial se complementa con la caracterización de otras categorías, permitiendo así la descripción de contextos de áreas de actividad en su interior (incluyendo la unidad doméstica); lo cual permitirá acrecentar el contenido de las inferencias entorno a las relaciones sociales de producción económica y reproducción biológica de aquellos grupos sociales que se desarrollaron en las diferentes regiones naturales de los Andes Centrales.

\footnotetext{
*Grados académicos: Estudios concluidos de Maestría en Arqueología Andina (Universidad Nacional Mayor de San Marcos). Diplomado en Formulación de Proyectos de Inversión (Universidad ESAN). Diplomado en Gestión Pública (Instituto de Gobierno y Gestión de la Universidad San Martin de Porres). Técnico en Diseño y Proyectos de Obras Arquitectónicas. Participación en diversos cursos y seminarios de capacitación en patrimonio cultural (a nivel nacional e internacional), y autor y editor de distintas publicaciones sobre patrimonio cultural. Institución en que labora: Consultor en Gestión de Proyectos Arqueológicos.

1. Lumbreras (1981), combinando condiciones de origen natural y social, divide el área andina en seis grandes áreas de integración económico-social: a.- El extremo norte o circum Caribe; b.- Los Andes Septentrionales; c.Los Andes Centrales; d.- Los Andes Centro Sur Circum Titicaca; e.- Los Andes Meridionales; f.- El extremo sur. Respecto a los Andes centrales, señala que este limita, en el extremo norte del Perú, con el desierto de Sechura, las sierras de Ayabaca y Huancabamba en Piura y por el sur con el nudo de Vilcanota y la región norte de Arequipa.
} 
Palabras claves: Unidad residencial, unidad doméstica, unidades de clasificación, áreas de actividad, arquitectura residencial, arquitectura doméstica.

\section{AbSTRact}

Summary a theoretical-methodological proposal for conceptualizing classification units referred to areas of activity that can be identified in association with prehispanic residential units of the Central Andes, as a result of formal and functional analysis of a representative sample of archaeological reports presented.

The conceptual definition of the residential unit is complemented by the characterization of other categories, allowing the description of contexts of activity areas inside (including the household); which allow to increase the content of environment inferences social relations of economic production and biological reproduction of those social groups that developed in the different natural regions of the Central Andes.

Keywords: Residential unit, household, classification units, activity areas, residential architecture, domestic architecture.

\section{Aspectos Preliminares}

El objetivo del presente trabajo es plantear un procedimiento teórico-metodológico que permita aproximarse al entendimiento de la función de la unidad residencial, a partir de la variabilidad y evolución del uso, forma y configuración de su espacio, como un aglutinante de unidades de clasificación que definan áreas de actividad.

Comprender la variabilidad sincrónica y diacrónica de los aspectos funcionales y de uso acerca de un espacio construido y/o acondicionado para residir, implica, en primera instancia, la definición y entendimiento de conceptos y categorías correspondientes a sus componentes asociados, que se manifiestan en contextos que demarcan áreas de actividad.

Un tipo de áreas de actividad, lo constituye la unidad doméstica. Al respecto, la conceptualización de unidad residencial y unidad doméstica ya han sido esbozadas por Noel (2009: 68):

"Existe una relación espacio - temporal entre una determinada unidad doméstica y una eventual unidad residencial, dicho enlace se caracteriza dentro de un colectivo social cuya complejidad determinará el correspondiente carácter socio - económico que les dio origen; es por ello que distinguirlos en su concepción permitirá establecer los primeros pasos en sus respetivos estudios:

La unidad doméstica es aquel contexto que manifiesta la realización de actividades que implican la satisfacción de una o varias necesidades básicas para la subsistencia por parte de un determinado individuo o grupo social. Ejemplo: la preparación y/o consumo de alimentos, vestido, etc.

Por otro lado, la unidad residencial resulta siendo un espacio acondicionado, el cual equivale a una vivienda, habitación, refugio, abrigo, etc.; pues es en la unidad residencial donde un individuo o grupo social pernocta y habita (ya sea temporal o permanentemente).

La unidad doméstica puede estar aislada o formar parte de una unidad residencial.

Dicho de otro modo, una unidad residencial puede contener a una unidad doméstica, pero esta también puede estar contigua o adyacente a la unidad residencial, o encontrarse simplemente cercana." (Fig. $\mathrm{N}^{\circ} 1$ ).

Cabe anotar que, por parte de varios autores, existe una confusión en la conceptualización de estas categorías ${ }^{3}$, lo que ha generado que no se tenga en claro la verdadera significancia que permita su 
contextualización adecuada en el desarrollo de inferencias y por ende el abordaje de su trascendencia económica y social; más aún, si a ello se agrega la relativa escases de investigaciones acerca de viviendas, incluso cuevas o abrigos rocosos, que fueron ocupados durante el desarrollo histórico - cultural prehispánico en los Andes Centrales.

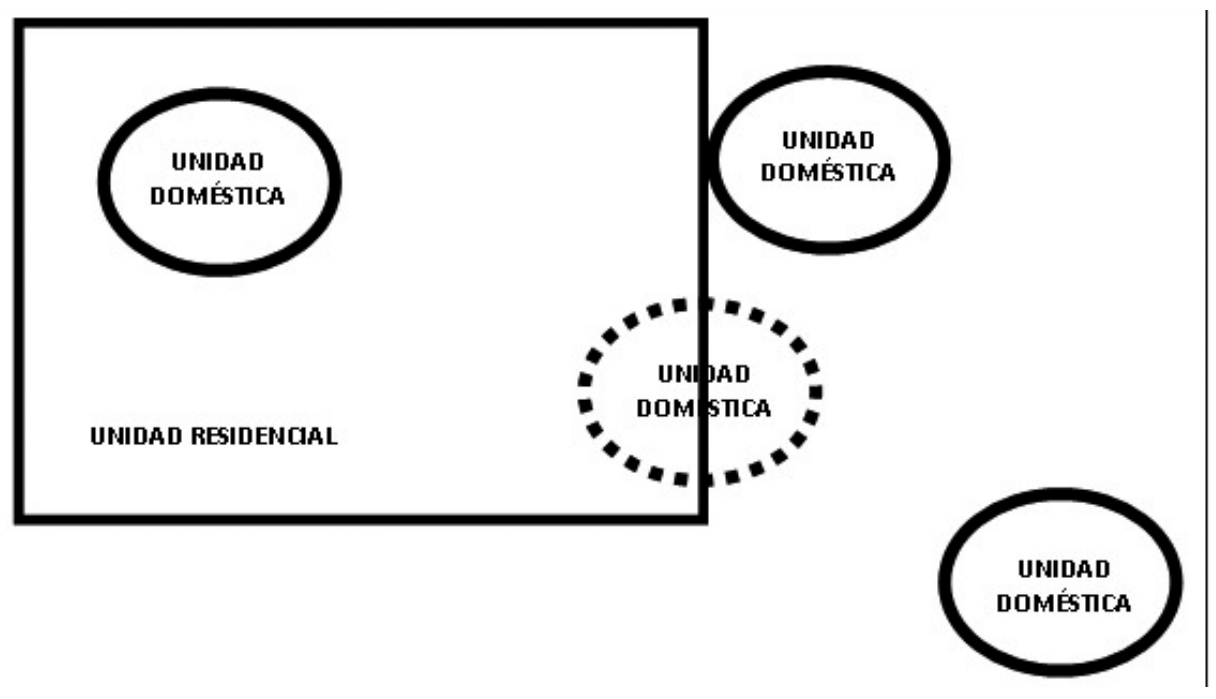

Figura 1.- Variabilidad de la ubicación contextual de la Unidad Doméstica con relación a la Unidad Residencial. ${ }^{2}$

Es necesario, por ello, el establecer unidades de clasificación para las áreas de actividad, que estén asociadas, directa o indirectamente, a la unidad residencial. En ese sentido, un muestreo de evidencias de unidades residenciales que presenten reportes de diversas áreas de actividad asociadas, constituye una tarea que exige seguir la continuidad de su variabilidad a través de una secuencia cronológica, para ello se empleará la secuencia cronológica establecida por Lumbreras (1981: 71) ${ }^{4}$, la cual se muestra a grandes rasgos en el siguiente cuadro:

Para alcanzar el ordenamiento testimonial y sus respectivas inferencias en hechos históricos, que a la postre permita un nivel explicativo concerniente al modo de vida asociado a la variabilidad de actividades desarrolladas en unidades residenciales, es necesario establecer la respetiva correspondencia entre las referidas unidades con su ubicación en los asentamientos y el grado de desarrollo de las fuerzas productivas; por lo que es fundamental la aproximación a la explicación de las relaciones existentes entre el individuo, su entorno social (principalmente familiar) ${ }^{5}$ y su entorno geográfico, a través

2. Tomado de Noel (2009: 68).

3. La confusión más usual se da con la conceptualización de la unidad doméstica, pues para algunos autores es sinónimo de vivienda o residencia (p. ej. Manzanilla 1986, Goldhausen y otros 2006; Makowski 2006, Shady 2006, Canziani 2009, entre otros.) y para otros es equivalente a una familia (p. ej. Shimada 1994, Pease y otros 1999, Dillehay 2006, entre otros).

4. Dicha secuencia cronológica está constituida sobre la base de un criterio económico-social, pero cuyos límites temporales no son rígidos, pues cada cuenca ha permitido niveles de desarrollos desiguales, sólo perceptibles a la luz del engranaje de los hechos históricos inferidos a partir del análisis y organización de las evidencias arqueológicas. 


\begin{tabular}{|c|l|}
\hline Cronología (aproximada) & \multicolumn{1}{c|}{ Etapas } \\
\hline $10000-5000$ a. C. & Lítico \\
\hline $5000-1800$ a. C. & Arcaico \\
\hline $1800-500$ a. C. & Formativo \\
\hline 500 a. C. -700 d. C. & Desarrollos Regionales Tempranos \\
\hline $600-1000$ d. C. & Imperio Wari \\
\hline $1000-1450$ d. C. & Estados Regionales y Señoríos Tardíos \\
\hline $1450-1532$ d. C. & Época Inca \\
\hline
\end{tabular}

Cuadro $N^{\circ}$ 1.- Secuencia cronológica del desarrollo histórico-social prehispánico en los Andes Centrales.

de sus elementos en el proceso productivo ${ }^{6}$ y sus formas de organización técnica de la producción ${ }^{7}$, en concordancia con la accesibilidad y transformación de los recursos vitales para su subsistencia.

\section{Algunas EVIDENCIAS DE MULTIPLICIDAd DE ÁREAS DE ACTIVIDAD ASOCIADAS A UNIDADES RESIDENCIALES PREHISPÁNICAS EN LOS ANDES CENTRALES}

El proceso del despliegue histórico del hombre en los Andes Centrales fue un tortuoso sendero del desarrollo de las fuerzas productivas (herramientas, fuerzas motrices utilizadas por el hombre, procedimientos laborales, división del trabajo y su racionalización, etc.), cuyas características definieron sus relaciones sociales, dando origen a una diversidad de campamentos líticos, ocupados por individuos que forjaron interacciones y estrategias trashumantes; dando paso, posteriormente, a la sedentarización, con la proliferación de aldeas, mostrando avances en lo que respecta a la apropiación de recursos y sus respectivas transformaciones; dicho proceso presentó progresos cualitativos que fueron sintetizados en la acumulación de experiencias varias, canalizadas y reflejadas, en gran medida, con el impulso del desarrollo en el diseño y construcción de edificaciones de carácter diverso, bajo la conformación de una formalización dentro de lineamientos de planificación urbana que se hallan presentes desde los 3000 a. C. aproximadamente. La sistematización en la apropiación de recursos y la creciente complejidad en la organización social, política, militar, administrativa y religiosa de diferentes sociedades, culminó en una síntesis reflejada en la instauración y expansión del imperio del Tawantinsuyu (1450 - 1532 d. C.).

5. El entorno social directo del individuo resulta ser aquello que es denominado la familia, la cual tiene su origen en el establecimiento de una alianza entre dos o más grupos de descendencia a través del enlace matrimonial entre dos de sus miembros (Lévi-Satrauss 1977). Dependiendo de la naturaleza de las relaciones de parentesco entre sus miembros, una familia puede ser catalogada como familia nuclear o familia extensa.

6. Son los elementos que intervienen en el proceso de trabajo: fuerza de trabajo, objetos de trabajo, medios o instrumentos de trabajo, productos y desechos. 
En cada asentamiento andino, hubo espacios diferenciados; pero en lo que respecta a la cotidianeidad, al modo de vida, es necesario comprender las motivaciones que generaron la variabilidad de actividades en el interior de las unidades residenciales o en su entorno directo.

Algunos ejemplos de reportes de áreas de actividad asociadas a unidades residenciales se muestran a continuación ${ }^{8}$ :

\section{Lítico (10000 - 5000 A. c.)}

El Paijanense es una tradición, cuya principal manifestación material se plasma en una industria lítica (puntas de forma triangular con bordes laterales rectos o cóncavo-convexos y pedúnculo delgado), la cual se desarrolló, fundamentalmente, en la zona desértica de Cupisnique, entre los valles de Chicama y Jequetepeque, en la costa norte del Perú, comprendiendo una serie de sitios que se encuentran ubicados a campo abierto, estos “...se identifican como campamentos, talleres y canteras" (Canziani 2009: 45). Respecto a su cronología Chauchat (2006: 367) señala que “...el conjunto de fechas sobre carbón de Cupisnique indica que el Paijanense está comprendido entre 10720 antes del presente (8770 antes de J.C.) y 7940 antes del presente (5990 antes de J.C.)."

Si bien, las evidencias reportan que en los campamentos destaca la presencia de una serie de fogones, algunos destinados a la preparación de alimentos, también se han hallado enterramientos humanos asociados a dichos campamentos. En estos casos se ha documentado el desarrollo de ciertas prácticas funerarias que habrían implicado la posible presencia de petates como envoltorio, la cremación parcial de los cuerpos, al igual que la presencia de vértebras de pescado perforadas y cuentas de hueso, que habrían sido parte de collares u otros elementos de adorno corporal. (Chauchat 2006; Canziani 2009).

Briceño y Millones (1999) investigaron en las quebradas de Cuculicote y de La Calera, a unos $5 \mathrm{~km}$ al noreste de la ciudad de Ascope, en la margen derecha del Chicama, permitiendo registrar aspectos del comportamiento de los paijanenses en relación a algunos recursos claves:

En la zona de Cupisnique, el Sitio PV22-13, ubicado en Pampa de los Fósiles, sobre una terraza aluvial, contiene 98 unidades entre talleres y campamentos y que, comprende un área de $2 \mathrm{~km} 2$. En la Unidad 2 se halló seis concentraciones de materiales, una de la cuales era de gran extensión. Incluye utillaje típico de áreas de campamento y dos entierros ${ }^{9}$, complementado con la presencia de los restos de un posible fogón y dos batanes. Es recurrente que los entierros de individuos estudiados para Cupisnique y Santa María estén colocados en las áreas de campamentos o asociados a ellos (Briceño y Millones 1999: 59- 60, 63).

En la Quebrada Cuculicote, Gálvez (1992) identificó dos tipos de campamentos: con basural y aquellos con una mezcla de actividades de taller más campamento. Efectivamente, la Unidad 12 (PV23-62) estaba ubicada a unos $80 \mathrm{~m}$ al suroeste de la unidad precedente. Su área, de unos $150 \mathrm{~m} 2$, contiene material lítico, un basural y ocho estructuras. La asociación del material lítico -inclusive lascas extraídas con percutor blando y artefactos de unifaces- con los restos orgánicos dentro de las estructuras, es una prueba de la contemporaneidad de las actividades de talla y las domésticas, pues no hay duda de

8. El subrayado es nuestro. Se resalta aquellas evidencias que demuestran la diversidad de actividades que estuvieron asociadas a la unidad residencial.

9. La Tumba 1 contiene un adolecente entre 12 a 13 años y la Tumba 2 corresponde a un individuo adulto el cual se encontró a $50 \mathrm{~cm}$ de distancia del entierro del niño. (Briceño y Millones 1999: 60). 
que los fogones sirvieron para preparar los alimentos. Es obvio que luego de cumplir con su función, las estructuras fueron llenadas con los desperdicios para facilitar otras tareas. (Gálvez 1992: 23- 24).

Por otro lado, en la puna de Junín, en san Pedro de Cajas, se ubica el sitio de Telarmachay, a una altitud de $4420 \mathrm{msnm}$, donde Lavallée (1995) llegó a definir un proceso de domesticación de camélidos alrededor del 3500 a. C., infiriendo el desarrollo y distribución espacial de una serie de actividades y procesos productivos, como la confección de determinados artefactos líticos, el destazado de los animales cazados, el curtido de las pieles o la preparación y consumo de alimentos, entre otras. De igual manera se definieron áreas asociadas a fogones en el interior del refugio, que presentaban una superficie relativamente limpia de fragmentos y que, coincidentemente, estaban demarcadas por concentraciones de piedras que señalaban el apuntalamiento de postes, destinados aparentemente al soporte de pieles tendidas a modo de paravientos, conformando una suerte de viviendas primitivas.

\section{Arcaico (5000 - 1800 A. C.)}

En la costa surcentral se ha reportado unidades residenciales en la aldea de Paloma: 613, la cual ocupa un área de 600 m NS y 250 m EO, en una pampa de formación vegetal de lomas, a unos 8 km al norte del río Chilca, $18 \mathrm{~km}$ al sur del río Lurín y $4.5 \mathrm{~km}$ de la playa.

Las excavaciones indican que casi todos los entierros estaban asociados a las viviendas al momento de su abandono. Se ha registrado cuerpos extendidos y envueltos en petates de totora, sepultándolos con algunas ofrendas bajo el piso de las viviendas (Canziani 2009: 63). Benfer (1999: 223) anota que los hombres fueron enterrados en la parte oriental de la casa, mientras que las mujeres en la oriental y los niños en una línea imaginaria nororiental que separa los adultos de ambos sexos, lo cual sólo ocurre en el estrato \#200.

Las viviendas eran unas chozas, algunas de la cuales mostraron un piso cubierto con esteras. Se han descubierto fragmentos in situ, amarrados a los postes interiores de la pared. Aislando cualquier inconveniencia del suelo, las esteras brindarían comodidad para el descanso, en las noches, al calor e iluminación de una pequeña fogata, lo que de paso ahuyentaría a las alimañas peligrosas del "hábitat" de lomas. En el interior de las chozas quedaron rezagos de las fogatas y en el exterior, los fogones ovalados de cocina, delimitados con piedras. En las inmediaciones de las viviendas se localizaron numerosos pozos de diferentes dimensiones; algunos de los más grandes habrían estado techados. (Fung 1999: 162-165).

En el sitio arqueológico de Pernil Alto, emplazado en una ladera seca de la margen derecha del valle medio del río Grande, a unos $6 \mathrm{Km}$ al noroeste de la ciudad de Palpa, en la costa sur del Perú, se han hallado restos de viviendas y entierros pertenecientes a una ocupación del Arcaico Medio. Se ha puesto al descubierto una serie de matrices o depresiones de contorno circular u ovalado excavadas en el terreno natural, las cuales tienen $3 \mathrm{~m}$ de diámetro promedio y entre 0.80 a $1 \mathrm{~m}$ de profundidad. Varias de estas matrices presentaban restos de apisonados, zonas de quema, artefactos líticos y deshechos de actividad doméstica, lo que indica que se trata de viviendas semi-subterráneas. Restos de postes $\mathrm{u}$ hoyos rellenados alrededor de las matrices indican que las viviendas tenían paredes y techos sencillos conformados por palos y ramas. Fechados de radiocarbono de los restos orgánicos indican que uno de los entierros data entre los años 3800 y 3380 a. C. (fechados con un sigma de calibración). (Isla 2010: 17-21).

Caral es un sitio arqueológico que se ubica en la margen izquierda del valle medio del río Supe, a 350 msnm, provincia de Lima, en la costa norcentral del Perú. Cronológicamente pertenece al Arcaico 
Tardío. Presenta una serie de edificaciones, donde las unidades residenciales comparten una serie de componentes y en ellas se efectuaban actividades domésticas, de manufactura, sociales y ritua$\underline{\text { les. }}$ Precisamente, en el denominado Conjunto Residencial Menor cada módulo habitacional tiene un vano posterior que comunica con patios y recintos anexos, en los cuales se llevaban a cabo actividades domésticas y de producción. (Shady 2005: 122, 126).

En los valles de Pativilca y Fortaleza, se han identificado al menos dieciséis sitios con evidencias de superficie de características del Arcaico Tardío, cuyas dimensiones varían desde diez hasta más de cien hectáreas. Los sitios cuentan “(...) con grandes áreas con restos de arquitectura residencial asociada, tal como señalan las evidencias procedentes de la superficie y de pozos de prueba en superficies estratificadas de viviendas. Las excavaciones revelaron restos de basura doméstica estratificada de 50 a 200 centímetros de profundidad". (Hass, Creamer y Ruiz 2004: 1021).

\section{Formativo (1800 - 500 A. C. $)$}

El sitio arqueológico de Cardal se ubica sobre la margen izquierda del valle bajo de Lurín, en la costa centrosur del Perú, a unos trece kilómetros del mar y a menos de un kilómetro del río.

Aunque no se ha definido a cabalidad la variabilidad de actividades que se desarrollaron en el entorno de la edificación ceremonial, cabe destacar el hallazgo en las inmediaciones del lado sur del montículo central, de una serie de construcciones rústicas asociadas a la deposición de basura que contenía restos de mariscos, pescados, mamíferos marinos, venados y aves, así como de ollas llanas y fragmentos de figurinas, lo que hace presumir que se trataría de estructuras domésticas. "Estas presentan muros bajos de piedra, que pudieron ser complementados con construcciones elaboradas con materiales perecederos, a modo de quincha. Algunas de estas estructuras pudieron funcionar como viviendas, otras para facilitar el almacenamiento, o como espacios libres, a modo de patios, para desarrollar la preparación de alimentos y otras actividades productivas asociadas a las unidades domésticas." (Canziani 2009: 153).

Al sur de la Península de Paracas, frente a la Bahía de la Independencia, en una zona absolutamente desértica, localizados respectivamente a más de 30 y 40 kilómetros al sur de Paracas y entre 50 y 45 kilómetros al oeste del valle medio de Ica, J. C. Tello identificó extensos sitios, entre los que destacan Chuchió y Karwa (Carhua), que presentan montículos con acumulaciones de grandes basurales con conchas marinas, y restos de habitaciones subterráneas o semisubterráneas, asociadas a cerámica incisa y polícroma del estilo Cavernas y con la presencia de enterramientos de fardos funerarios similares a los hallados en la península (Tello y Mejia Xesspe 1979: 92; Canziani 2009: 173).

\section{Desarrollos Regionales Tempranos (500 a. C. -700 d. C.)}

En lo que respecta a la costa sur del Perú, Carmichael (1994: 230) lamenta que el contexto doméstico Nasca permanezca inexplorado. Lo exiguo de las excavaciones en áreas habilitaciones aún constituye una barrera mayor para un mejor entendimiento de la cultura Nasca y su producción cerámica.

Otro panorama se muestra en la costa norte: Una expresión socio económica denominada Gallinazo, conocida también como Virú, se desarrolló en la costa norte luego de Salinar y antecede el posterior desarrollo de la cultura Moche. Fue en el valle de Virú, inmediatamente al sur de Trujillo, donde la cultura Gallinazo alcanzó su mayor desarrollo. Como parte de los asentamientos rurales se identificaron también, en la parte media alta del valle, algunas grandes casas aisladas, compuestas por uno o dos cuartos principales a los que se les adosan otros cuartos más pequeños o depósitos. (Canziani 2009: 184, 192). 
Entre el valle bajo y medio de Moche, en la margen sur, se encuentra Cerro Blanco, con una altura de $500 \mathrm{~m}$. En la ladera oeste se halló evidencias de una ocupación del Formativo Superior, y la planicie fue ocupada por el complejo de la Huaca del Sol y la Luna, que cubrió una ocupación Gallinazo.

En dicha planicie, que separa las Huacas del Sol y de La Luna, se halla el Conjunto Arquitectónico 35, abarcando un área total de $495 \mathrm{~m} 2$. (Tello y otros 2008: 96, 139). Así mismo, el referido conjunto presenta seis pisos de ocupación: Los pisos 1 y 2 están asociados a la cerámica Moche IV y los pisos del 3 al 6, a la cerámica Moche III de la secuencia estilística establecida por Larco (1948).

En los conjuntos habitacionales se desarrollaron tanto actividades domésticas como también actividades productivas o administrativas. Su carácter doméstico está evidenciado por una serie de rasgos característicos, entre ellos, la presencia de ambientes destinados a la cocina, donde es típico hallar fogones hechos con dos hileras paralelas de adobes de canto, que servían para contener la brasa del fogón y apoyar las ollas durante la cocción de los alimentos. En estos mismos ambientes, o en otros anexos a ellos, se realizaban tareas complementarias a la preparación de alimentos, como la molienda, documentada con la presencia de batanes y manos de moler. Asociados a este tipo de actividades domésticas se encuentran también algunos pequeños espacios, a modo de botaderos, que habrían sido destinados para la acumulación de los desperdicios generales dentro de la vivienda. Los conjuntos habitacionales dispusieron también de facilidades destinadas al almacenamiento. Tal es el caso de la existencia de pequeños cubículos que pudieron servir para depósito de granos u otro tipo de productos alimenticios, así como para determinados insumos destinados a la producción. Contaron también con nichos y hornacinas útiles para guardar desde enseres hasta objetos de culto. Además, se registró la recurrente presencia de tinajas semienterradas en los pisos, que parece sirvieron para disponer de agua. En otros casos, ciertos ambientes que presentan la singular disposición de una serie de tinajas o vasijas ordenadas en hilera y empotradas sobre poyos, sugieren el requerimiento de acumular abundantes cantidades de líquidos para alguna actividad en especial. (Canziani 2009: 195, 213, 216). Cabe agregar, que en el Conjunto Arquitectónico 35, se han hallado 28 personas sepultadas en distintos momentos, durante el proceso de remodelación y sellado de recintos. (Tello 2008: 200).

\section{ÉPOCA WARI $(600$ - 1000 D. C.}

En el área de influencia de la Mina Pierina, en una meseta altoandina a una altitud promedio de 4,100 msnm, en el lado oriental de la Cordillera Negra, en el Callejón de Huaylas, sierra de Ancash, un grupo de pastores se instaló durante la Época Wari (650-950 d. C). Tal es el caso de Ancosh Punta (Pan 5-5), un sitio arqueológico que se sitúa en una suave colina con bajos desniveles a manera de pampa en plena ecología de puna a 4190 m de elevación, donde se contaron entre 10 a 12 recintos bastante grandes (6 por $10 \mathrm{~m}$ aproximadamente). Ponte $(2007: 101,104)$ registra:

"una estructura habitacional de forma rectangular con un lado abierto en forma de U estaba insertada entre los gruesos muros de pirca que forman los corrales; midiendo 3.4 por $4 \mathrm{~m}$; un pequeño fogón circular fue hallado en la esquina sudoeste adosado a la estructura y se caracteriza por tener lajas puestas en canto asociado a un área con lentes de carbón y fragmentos cerámicos; también fue posible encontrar una gran cantidad de lascas, algunas puntas de obsidiana y puntas pulidas de pizarra y lutita en áreas específicas de la habitación que demostrará cierto repartimiento preferencial de elementos y actividades en contextos fijos."

Nawinpukyo es generalmente conocido como uno de los principales sitio arqueológicos de la sociedad Huarpa de los Desarrollos Regionales Tempranos (ca. 200 a. C. - 600 d. C.) en Ayacucho. Sin embargo, recientes investigaciones han demostrado que la ocupación Wari (ca. 600 - 1000 d. C.) fue también importante, perdurando durante varios siglos. 
Ñawinpukyo se localiza sobre una colina rocosa del mismo nombre a unos $5 \mathrm{~km}$ al sureste del centro de Ayacucho. La colina alcanza una altura máxima de $3007 \mathrm{msnm}$, lo que le otorga una visión dominante de la parte sur del valle de Ayacucho. La ocupación Wari consistía en por lo menos tres conjuntos residenciales, denominados Grupos Arquitectónicos Sureste, Noreste y Central respectivamente. Los conjuntos residenciales se distribuían espacialmente sobre la cima de la colina, asociándose directamente con espacios abiertos, campos y terrazas de cultivos localizados a su alrededor. Los cuartos suelen disponerse en torno a un patio o área abierta que se utilizaba para una amplia gama de actividades domésticas y rituales. Algunos recintos se agregaban y otros eran reemplazados, cubriéndose ritualmente tras la muerte de sus ocupantes. Al respecto, se han hallado cierto número de tumbas en cuartos del Grupo Arquitectónico Sureste que fueron probablemente construidos durante la parte inicial de la Época Wari (ca. Siglo VII d. C.) y usados interrumpidamente hasta el siglo IX o X d. C. (Leoni 2007: 131-132, 140-141, 143).

\section{Estados Regionales y Señoríos Tardíos (1000 - 1450 d. C.)}

Huaquiná Este T34 es un sitio arqueológico, de más de $500 \mathrm{~m}$ de longitud, con una ocupación que parte desde la Épocas Wari. Se encuentra en la línea divisoria entre los departamentos de Lima e Ica, a unos $200 \mathrm{~km}$ al sur de Lima y unos $15 \mathrm{~km}$ al norte de Chincha Alta. En la parte media del valle de Topará, situada entre los ríos de Cañete al norte y los ríos de Chincha al sur (río Matagente y río San Juan).

Presenta un ordenamiento ortogonal con recintos habitacionales de planta rectangular u ovoidal, construidas de "pirca", adaptadas a la topografía y aglutinados alrededor de varias plazas rectangulares. Se distinguen viviendas con puertas estrechas y estrechos callejones. Los corredores de acceso mayormente están dispuestos en ángulos en forma de L. Un detalle arquitectónico muy frecuente son los desniveles dentro de un solo cuarto en forma de tarimas y banquetas. Dentro de estos recintos también se observaron tumbas con construcciones rectangulares y depósitos subterráneos con planta circular, alineadas en filas.

Una de estas unidades fue excavada completamente, descubriendo un área de unos 25 por 25 metros con 7 recintos arquitectónicos relacionados entre sí. El material cultural recuperado indica que los diferentes recintos eran dedicados a diversas labores domésticas y posiblemente en parte a usos ceremoniales, además contenían una tumba en forma de pozo empotrado con más de 20 entierros secundarios. Se hallaron grandes fogones, abundante cerámica de cocina, restos de cuyes y llamas, y cuantioso material botánico. La cerámica parte de la época Wari hasta Estados Regionales incluyendo toda la tradición Chincha con por lo menos seis alfares diferentes. (Wurster 1997: 13, 20-22).

El Complejo Arqueológico de Chan Chan se ubica en la costa norte peruana, en el valle del río Moche, a pocos kilómetros al norte de la ciudad de Trujillo. Los restos de este extenso centro urbano cubren un área de aproximadamente veinte kilómetros cuadrados. Presenta una serie de "complejos arquitectónicos de elite", con estructuras de planta ortogonal, construidos con muros de adobe. Se trata de estructuras residenciales, en su mayoría, asociadas a la presencia de pozos que permitían el abastecimiento de agua.

Así mismo, se hallan los denominados "barrios populares", con estructuras de función habitacional y productiva, separados por pasajes que permitían la comunicación entre ellos y articulaban los barrios con el resto de la ciudad. En las áreas libres de los conjuntos de carácter habitacional se ha registrado el desarrollo de actividades domésticas asociadas a la presencia de fogones, batanes y otras evidencias de la preparación de alimentos. Se distinguen los llamados 'barrios' con población dedicada a la producción artesanal, principalmente; también aquellos 'barrios' que parecen corresponder 
a las personas adscritas al servicio de la elite de los complejos político-administrativos y que se ubican en las proximidades de estas; y de estructuras con corrales posiblemente asociadas con grupos de tratantes o mercaderes relacionados con el manejo de las caravanas de llamas y el intercambio a distancia a lo largo de la costa norte y hacia las regiones cordilleranas. (INC 2000; Canziani 2009: 369, 375-379).

En la costa centrosur peruana, en lo que se refiere al área inmediata del valle de Lurín, además de Pachacamac, existen varios poblados, aldeas y caseríos; tal es el caso de Chontay, un sitio arqueológico con una gran cantidad de silos o qollqas de depósito, construidos bajo el piso de la mayoría de la viviendas, revelando una notable capacidad de almacenamiento de productos, cuyo volumen excede ampliamente los requerimientos del consumo familiar. (Canziani 2009: 408, 410).

\section{ÉPoca INCA (1450 - 1532 D. C.)}

En lo concerniente a las viviendas de la Época Inca, Waldemar Espinoza (1997: 165) anota que muchas de las casas serranas contaban con un grupo de habitaciones independientes, construidas circundando un patio central. Todo el conjunto permanecía rodeado por una cerca que sólo tenía una puerta para entrar y salir. Efectivamente, tal característica ya había sido advertida por Gasparini y Margolies (1977: 137): "Las casas unifamiliares de los campesinos Inka, llamadas wasi, estaban reunidas en grupos, ubicadas libremente pero respetando un cierto orden hacia los espacios destinados a la circulación."

En la margen izquierda del valle medio del Rímac, en la parte este de la ciudad de Lima, costa central del Perú, Villacorta (2004) ha identificado una particular manifestación de arquitectura monumental: palacios o residencias de elite. Los cuales habrían excedidos a la sola función doméstica. Su complejidad se sustenta en la complejidad de la toma de decisiones -exclusivas de sus ocupantes principales-, que conciernen al control, transformación y administración de los recursos materiales e ideológicos de una sociedad determinada. Una de estas edificaciones es Puruchuco, constituido por un muro perimétrico que aísla al edificio, la existencia de un solo acceso, un patio interior y una terraza o plataforma que, junto con la última, configuran la audiencia. En su área reservada se encuentran ambientes compatibles con la actividad residencial; en otro sector aparecen asociados un patio con depósitos interiores. En el último caso es evidente que el patio corresponde a zonas de laboreo donde se procesaban los productos almacenados en lo depósitos contiguos.

Para culminar este muestreo, resulta interesante mencionar, en el marco del tema abordado, un caso de práctica mortuoria para los Andes Septentrionales, muy cerca de la actual ciudad de Quito, dato registrado por el cronista Cieza de León (1973 [1548 - 1550]: 119), quien anotó una de sus impresiones llevadas a cabo en un pueblo que había sido conquistado por el ejercito incaico: "Estos aposentos de Riobamba ya tengo dicho cómo están en la provincia de los Puruaes, que es de lo bien poblado de la comarca de la ciudad de Quito,(...) A los señores, cuando se mueren, les hacen, en la parte del campo que quieren, una sepultura honda cuadrada, a donde le meten con sus armas y tesoros, si lo tiene. Algunas de estas sepulturas hacen en las propias casas de sus moradas; guardan lo que generalmente todos los más naturales de estas partes usan; que es echar en las sepulturas mujeres vivas de las más hermosas;..."

\section{USO Y FUNCIÓN DE LA UNIDAD RESIDENCIAL: DEFINIENDO UNIDADES DE CLASIFICACIÓN PARA ÁREAS DE ACTIVIDAD}

Los reportes de actividades en unidades residenciales son escasos y fragmentarios, debido en parte a que por sobre ella se prioriza la investigación de la "arquitectura pública" ${ }^{10}$, más aún si esta presenta 
tectura doméstica" y “arquitectura residencial”, conceptualizándolos indistintamente como si fuesen categorías que definen por igual a una vivienda.

El abordar aspectos concernientes a la variabilidad de actividades en asociación a una unidad residencial exige la distinción en entre dos aspectos: El modo o modos de empleo, es decir el uso, y la finalidad con la cual fue concebida, o sea, la función que se le otorga a la referida unidad.

Por ejemplo, un abrigo rocoso, una cueva, pudieron constituir una unidad residencial; al igual que una vivienda (edificación previamente diseñada), las cuales cumplieron la finalidad de refugio, función fundamental, pero cabe señalar que en correspondencia a las demarcaciones espaciales internas y la actividad o actividades que en ellas se realizaron, permanentes o temporales, el empleo o uso de dicha unidad se pudo diversificar.

La “arquitectura residencial” prehispánica es aquella que se erigió para que cumpla, principalmente, una función habitacional; por tanto, una parte considerable de su espacio interno fue usada para pernoctar, sin que ello haya excluido otras actividades complementarias.

Entre las áreas de actividad que se pueden identificar en las unidades residenciales, se encuentran las domésticas (generadoras de contextos que manifiestan unidades domésticas).

Cabe señalar, que dichas actividades, que implicaron la satisfacción de una o varias necesidades básicas, no necesariamente se desarrollaron en un determinado espacio construido.

Sin embargo, se puede denominar "arquitectura doméstica", a aquellos espacios que fueron delimitados constructivamente para el desarrollo de una actividad que satisfizo una necesidad básica, como por ejemplo la preparación de alimentos.

De lo dicho, se colige que el categorizar un determinado espacio, donde se hallan evidencias de la realización de cualquier actividad social, con un término precedente como el de "arquitectura", resulta siendo limitante, pues la actividad a identificarse no siempre se halla inscrita en un espacio construido específicamente para tal o cual fin.

En ese sentido, en el marco de cualquier proceso de investigación sobre áreas de actividad, se puede plantear el establecimiento de categorías definidas como unidades de clasificación, con el objetivo de llegar a un mejor entendimiento de todas aquellas actividades que se efectuaron en un determinado asentamiento arqueológico.

Los contextos que permiten identificar áreas de actividades en asociación directa a una unidad residencial, pueden estar circunscritas a un espacio construido o no, en conformidad a la particularidad del modo de vida del grupo social que la ocupó, cuyas expresiones fenoménicas, materializadas en

10. Canziani (2009: 64, nota de pie de página $n^{\circ}$ 3) indica que "por arquitectura pública, consideramos todas aquellas edificaciones cuya función está referida a actividades de carácter especializado. Esta función se expresa tanto en la forma arquitectónica como en la propia producción constructiva, y se define científicamente mediante el análisis arqueológico de sus contextos y asociaciones. En este sentido, la arquitectura pública se diferencia claramente de la arquitectura doméstica, que resuelve las funciones habitacionales y las actividades propias de núcleos familiares. Con el surgimiento de la arquitectura pública se constituye una nueva clase de arquitectura que abarca una amplia gama de funciones, sean estas de tipo ceremonial, político, administrativo, productivo, militar, etcétera. Lejos del equivoco que considera la arquitectura pública con relación a su capacidad de albergar una determinada cantidad de personas -público-, el carácter de esta está definido sustancialmente por la calidad de las funciones especializadas que contiene, independientemente de las dimensiones físicas que estas requieran para su realización." 
restos arqueológicos definidos contextualmente, forman parte del conjunto de unidades de clasificación para áreas de actividad que pertenecen a un espacio y tiempo determinado.

La caracterización del contenido de los elementos contextuales de las referidas unidades de clasificación, se diferenciará, por cuanto cada sociedad habría tenido un modo y sub modos de vida que variaron según la disponibilidad de recursos y su respectiva correspondencia al grado de desarrollo de sus fuerzas productivas, en el marco de su formación económico-social.

Al respecto, Manzanilla (1986: 14) considera que la unidad mínima significativa del contexto arqueológico es el área de actividad, porque revela patrones de comportamiento; ésta se define como la concentración y asociación de materias primas, instrumentos, desechos macroscópicos o invisibles (como los compuestos químicos) en superficies o volúmenes específicos.

A un nivel social, para Manzanilla (ob. cit.), “(...) la unidad mínima sería la doméstica, es decir; el área de residencia de un grupo determinado y sus áreas de actividad, entendiéndose por grupo doméstico a los individuos que comparten el mismo espacio físico para comer, dormir, descansar; crecer y procrear".

Si bien, Manzanilla considera una equivalencia entre unidad doméstica y la residencia, es necesario reiterar que ello no corresponde a un criterio adecuado en las definiciones, puesto que en una unidad residencial, además de actividades domésticas, se puede evidenciar contextos que manifiestan actividades de circulación interna, almacenamiento, crianza de animales, producción artesanal, aseo, descanso e incluso actividades rituales. Por otro lado, en algunos casos se ha reportado que la unidad residencial, luego de su abandono, fue usada para enterramientos de uno o más individuos, probablemente guardando el sentido de pertenencia a su morada y/o la relación de parentesco familiar.

En ese sentido, tomando en cuenta las evidencias arqueológicas sobre unidades residenciales y la diversidad de áreas de actividad asociadas a esta, ya sea en su interior o exterior, se propone distinguir dichas áreas de actividad en unidades de clasificación, en correspondencia al tipo de funciones y/o usos del espacio que en ella se dieron.

Al respecto, debe anotarse que algunas de las referidas unidades, si bien se presentan en asociación directa a la unidad residencial, también se pueden presentar en espacios independientes dentro del asentamiento.

De modo específico, en una unidad residencial se puede llegar a establecer una clasificación de ocho tipos de unidades para definir la contextualización de las áreas de actividad ${ }^{11}$, incluyendo la doméstica; tal como se desarrolla en el siguiente cuadro: 
Cuadro $\mathrm{N}^{\circ}$ 2.- Unidades de Clasificación para Áreas de Actividad asociadas a la Unidad Residencial

\begin{tabular}{|c|c|c|c|}
\hline \multicolumn{3}{|c|}{ UNIDADES DE CLASIFICACIÓN } & $\begin{array}{l}\text { POSIBLES REPRESENTACIONES } \\
\text { (EJEMPLOS) }\end{array}$ \\
\hline 1 & Unidad doméstica & $\begin{array}{l}\text { Variabilidad: } \\
\text { - Espacio para preparación y/o consumo de } \\
\text { productos básicos. } \\
\text { - Espacio de descanso o pernocte. }\end{array}$ & $\begin{array}{l}\text { - Estructura y/o elementos asociados que } \\
\text { fueron destinados a la cocción de } \\
\text { alimentos. } \\
\text { - Restos de un fogón y su entorno } \\
\text { directo. } \\
\text { - Recinto con banqueta. }\end{array}$ \\
\hline 2 & \multicolumn{2}{|c|}{ Unidad de producción especializada } & $\begin{array}{l}\text { - Un taller de producción alfarera, etc. } \\
\text { - Restos de talla de artefactos líticos. }\end{array}$ \\
\hline 3 & $\begin{array}{l}\text { Unidad de crianza } \\
\text { y/o reproducción de } \\
\text { animales }\end{array}$ & $\begin{array}{l}\text { Variabilidad: } \\
\text { - Espacio para la crianza y/o reproducción } \\
\text { de animales, para consumo } \\
\text { (alimentación) y/o intercambio. } \\
\text { - Espacio para la crianza y/o reproducción } \\
\text { de animales de carga para transporte y/o } \\
\text { acopio de materia prima. }\end{array}$ & - Un corral. \\
\hline 4 & \multicolumn{2}{|l|}{ Unidad de almacenaje } & $\begin{array}{l}\text { - Un pozo, etc. } \\
\text { - Un simple hoyo en la tierra con restos } \\
\text { de productos alimenticios o no. }\end{array}$ \\
\hline 5 & \multicolumn{2}{|l|}{ Unidad de desechos } & $\begin{array}{l}\text { - Espacio destinado a la acumulación } \\
\text { (temporal o permanente) de } \\
\text { desperdicios. }\end{array}$ \\
\hline 6 & \multicolumn{2}{|c|}{ Unidad de circulación y/o congregación } & $\begin{array}{l}\text { - Un patio, un corredor. } \\
\text { - Espacio abierto circundado por } \\
\text { viviendas (unidades residenciales). }\end{array}$ \\
\hline 7 & \multicolumn{2}{|l|}{ Unidad ceremonial } & $\begin{array}{l}\text { - Un altar u hornacina donde se coloca } \\
\text { ofrendas. } \\
\text { - Elemento o elementos asociados } \\
\text { depositados a manera de ofrenda. }\end{array}$ \\
\hline 8 & Unidad funeraria & $\begin{array}{l}\text { Variabilidad: } \\
\text { Tal como se advierte en los reportes, la } \\
\text { unidad residencial suele ser abandonada, } \\
\text { cambiando el uso/función concebido } \\
\text { originalmente. }\end{array}$ & $\begin{array}{l}\text { - Una cista, una tumba, etc. } \\
\text { - Restos óseos de uno o más individuos } \\
\text { cubiertos por restos de un refugio } \\
\text { abandonado. }\end{array}$ \\
\hline
\end{tabular}

El desarrollo conceptual de las referidas unidades de clasificación para áreas de actividad es el siguiente:

1. Unidad doméstica, representa la unidad básica de producción en la dimensión familiar y eventualmente fue también una unidad básica de reproducción. En general, es aquel contexto que manifiesta la realización de actividades que implican la satisfacción de una o varias necesidades básicas para la subsistencia (p. ej. la preparación y/o consumo de alimentos, elaboración de vestido, etc.). Además de la posibilidad de su contextualización a partir de la presencia de un espacio de preparación y/o consumo de productos básicos, también puede ser definido desde el hallazgo de un espacio de descanso o pernocte, tal como lo sería aquel contexto que evidencie un espacio que fue acondicionado sólo para pernoctar y/o reposar, el cual pudo estar delimitado y formando un recinto con acceso, muchas veces restringido.

Al respecto, Noel (2009: 68-69) precisa lo siguiente:

“Así mismo, debe tomarse en cuenta que en el interior de una unidad residencial se puede generar la reproducción biológica del ser social, la cual es la base de su filiación y parentesco en la esfera del modo de reproducción.

Queda entendido que el grupo social al cual se hace referencia es un conjunto de individuos ligados por su nexo en el modo de reproducción y producción del colectivo al cual pertenece, bajo afinidades de 
parentesco, sexo, edad, etc.; en ese sentido, la unidad básica de subsistencia de una sociedad concreta es la familia ${ }^{12}$.

Comprendiendo que una unidad doméstica expone prácticas asociadas con la reproducción biológica en un ámbito que por lo general se da en una unidad residencial, es que se presenta de modo particular en dos dimensiones simultáneas: la individual y la familiar, ambas contenidas por una general: la social o colectiva. (Fig. № 2).

La referida reproducción biológica se manifiesta fenoménicamente de dos maneras:

- La procreación cuantitativa de los individuos que se da en la dimensión familiar, y

- La cotidianeidad del mantenimiento de los individuos que se puede dar ya sea en la dimensión individual o en la dimensión familiar."

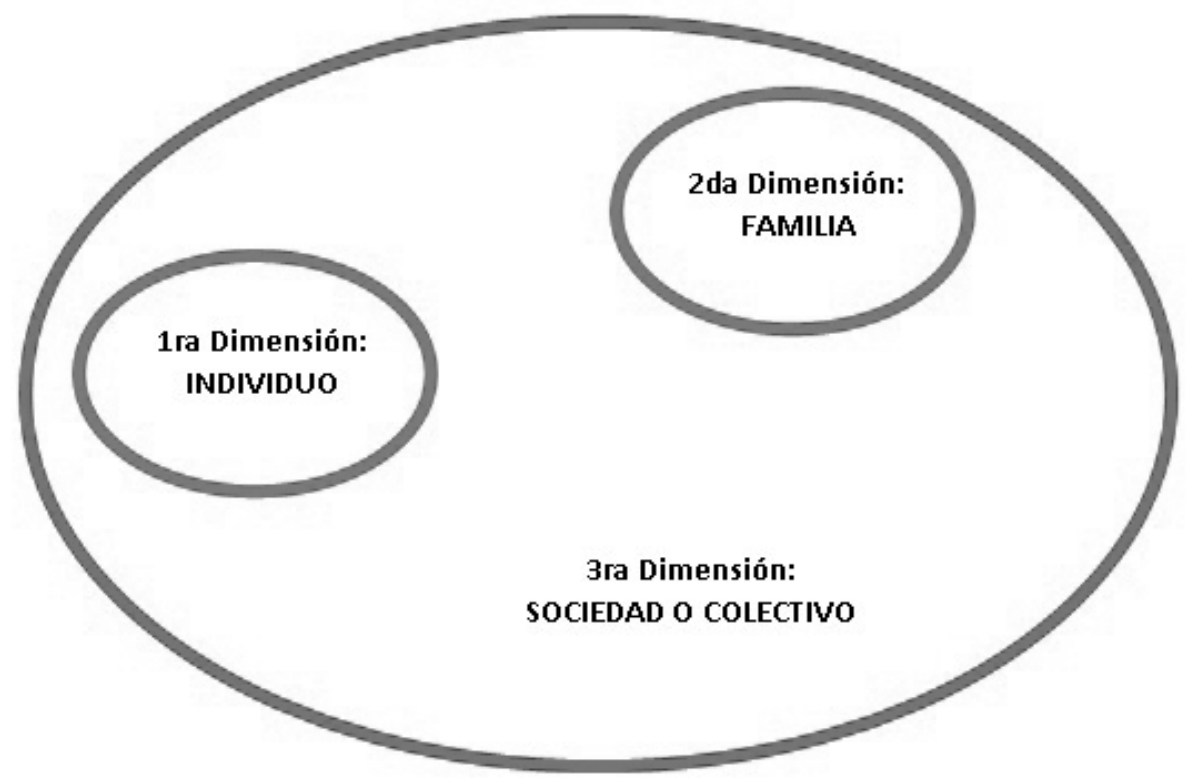

Figura № 2.- Dimensiones en las que se realiza la reproducción biológica.

Finalmente, Noel (2009: 70) indica lo siguiente: "Debe aclarase que una unidad doméstica constituye también una unidad básica de producción. Esta equivalencia responde a la expresión de un conjunto de relaciones sociales dentro de una organización económica nuclear correspondiente a una sociedad determinada". (Fig. № 3).

12. Federico Engels (1975 [1891: 491) citó a L. Morgan en las siguientes consideraciones sobre la familia: "La familia es el elemento activo; nunca permanece estacionada sino que pasa de una forma inferior a una forma superior a medida que la sociedad evoluciona de un grado más bajo a otro más alto. Los sistemas de parentesco, por el contrario, son pasivos; sólo después de largos intervalos registran los progresos hechos por la familia y no sufren una modificación radical sino cuando se ha modificado radicalmente la familia". 


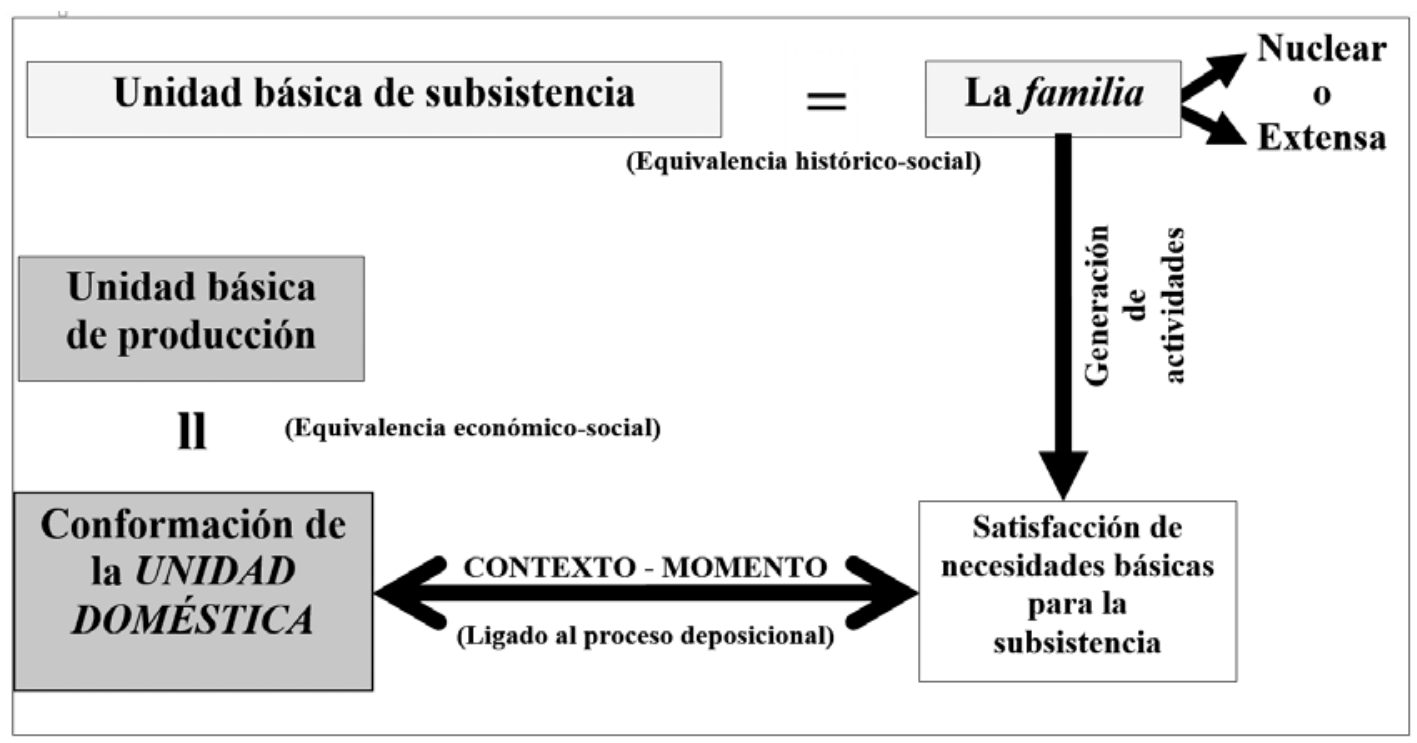

Figura № 3.- Equivalencia histórico-social de la familia en una sociedad concreta y la generación de la unidad doméstica en una organización económica nuclear. ${ }^{13}$

2. Unidad de circulación y/o congregación, espacio que permitió el tránsito o reunión de individuos en conexión con otros ambientes o edificaciones, con igual o diferente uso o función. Ejemplos: un pasillo, un corredor, un patio, una plaza, etc.

3. Unidad de crianza y/o reproducción de animales; al respecto debe indicarse que las sociedades prehispánicas inician su desarrollo a partir de una economía basada en la caza, recolección y pesca; posteriormente, la domesticación de plantas y animales, dio paso a su especialización en la reproducción. Tal es así que en los Andes Centrales, hace unos 6,000 años comenzó la domesticación de la llama (Lama glama), la alpaca (Vicugna pacos) y el cuy (Cavia porcellus) (Mazoyer, Marcel y Laurence Roudart 1997: 115).

Ejemplo de unidad de crianza y/o reproducción de animales: un corral.

4. Unidad de almacenaje, es aquel espacio donde se evidencia actividades de depósito o guardado de productos, manufacturados o no, con fines de subsistencia. Esta unidad puede ser administrada por quienes habitan la unidad residencial o haber tenido un carácter comunal e incluso estatal, pues podría ser tutelado por quienes controlaron la producción del asentamiento, sea una aldea o centro urbano. etc.

Ejemplos de una unidad de almacenaje son: un depósito, un corral, una colca, un granero, un pozo,

5. Unidad de producción especializada, es aquel espacio que fue acondicionado para que un individuo o un grupo de ellos establezca un sistema de organización entre los instrumentos de trabajo y objetos de trabajo, con la finalidad de obtener bienes que hayan permitido la satisfacción de las necesidades de los individuos del grupo social al cual perteneció o incluso haya sido destinado a otros grupos que formaron parte de la red del sistema administrativo integrado de la comunidad.

13. Tomado de Noel (2009: 70). 
El referido espacio, acondicionado de modo permanente o eventual, restringido o no, pudo estar asociado a una unidad residencial, sin que ello haya significado una restricción del destino final de dichos productos.

Ejemplo de unidad de producción especializada lo es un taller de producción de objetos necesarios para el proceso de transformación de un bien o producto básico (p. ej. alfarería) o de producción de bienes suntuarios, como cuentas, abalorios, etc.

6. Unidad de descarte o desecho, es el lugar que se halla en el interior o exterior de la unidad residencial destinado exprofesamente a la acumulación y/o eliminación de desechos de consumo o producción.

7. Unidad ceremonial, es aquel espacio, construido o no, donde se efectuaron ritos, sea en el ámbito privado (p. ej. unidad residencial) o público (p. ej. una plaza). Dicha unidad puede ser identificada a través de aquellos restos que fueron empleados durante acciones de culto o rituales.

Ejemplo de ello lo son aquellos contextos con una o varias ofrendas depositadas en algún recinto, previo enterramiento o clausura del mismo.

8. Unidad funeraria es el espacio acondicionado para enterrar a uno o varios individuos. Ejemplo de ello lo es una cista, una tumba, etc.

Cabe señalar, que una unidad ceremonial podría ser también una unidad funeraria, si es que en ella se hallan materiales que evidencien un ritual de enterramiento, como lo son los objetos u ofrendas que acompañan al individuo sepultado; incluso debe tomarse en cuenta el modo en que estos han sido colocados, pues la recurrencia en su deposición permitiría identificar, además, el patrón de enterramiento que singulariza parte de las creencias del grupo social al cual perteneció.

Se advierte que la diversidad de actividades asociadas a la unidad residencial, permite concluir que se trató de un espacio delimitado, acondicionado y muchas veces construido, el cual aglutinó, en su interior o en espacios adyacentes, el desarrollo de una o varias actividades, sea por un individuo o por una unidad social básica (por ejemplo la familia) o un colectivo más amplio.

En ese sentido, la unidad residencial prehispánica fue un espacio que en muchas ocasiones estuvo constituido por un conjunto de contextos, es decir, elementos que reflejan el desarrollo de actividades diversas; contextos que configuraron unidades de clasificación para áreas de actividad.

La diversidad de tipos de unidades de áreas de actividad que pudieron asociarse a una unidad residencial, se distinguen a partir de la configuración en su delimitación, pudiendo ser un espacio construido o no construido.

\section{Comentarios Finales y Conclusiones}

Si bien, son escasos y fragmentarios los reportes de áreas de actividad en unidades residenciales, en contraste, por ejemplo, con aquellas referidas a edificaciones "públicas", sobre todo monumentales, de carácter ceremonial, se ha podido establecer un muestreo de la variabilidad de áreas de actividad, a través de unidades de clasificación, asociadas a unidades residenciales prehispánicas.

Precisamente, se propone la distinción de ocho (8) unidades de clasificación de áreas de actividad asociadas a la unidad residencial:

Las primeras siete (7) estuvieron vigentes durante la ocupación dinámica de la unidad residencial: Unidad doméstica, unidad de producción especializada, unidad de crianza y/o reproducción de animales, unidad de almacenaje, unidad de desechos, unidad de circulación y/o congregación, y la unidad ceremonial. 
Sin embargo, la octava (8): la Unidad funeraria, suele ser un contexto constituido durante el proceso de abandono de la Unidad Residencial, cambiando el uso/función concebido originalmente.

Tal variabilidad, responde a un proceso de desarrollo socio-cultural, que se inicia desde la conformación de campamentos líticos, plasmando el origen de la evolución de la "arquitectura residencial", configurando nuevos diseños, en correspondencia con el grado de desarrollo de las fuerzas productivas, lo cual implicó cambios en el empleo de materiales y la técnica constructiva, permitiendo, finalmente, el registro de unidades residenciales no necesariamente cerradas y techadas totalmente, sino también, algunas con espacios asociados sin techar; otros, destinados a la producción y almacenamiento de bienes, como los depósitos, corrales e incluso corredores o pasajes que permitieron la comunicación con otras viviendas o con espacios de congregación más amplios, integrando unidades sociales básicas de la comunidad a la cual perteneció tal o cual unidad residencial.

Ello explicaría las disímiles caracterizaciones del espacio que se presentaron en el interior y exterior de la unidad residencial, a lo largo de la secuencia de la ocupación de un determinado grupo social, lo cual permite (con obvias limitaciones dadas en el registro de los testimonios) establecer la variabilidad de su conformación, identificando las áreas de actividad asociadas, reflejando, hasta cierto punto, el circuito económico nuclear que tuvo una unidad social de subsistencia (v. g. la familia), es decir, su modo de producción y reproducción.

Por otro lado, debe acotarse que en aquellos tiempos en que diversas comunidades de cazadores - recolectores fueron asentándose en distintas partes del territorio andino, también se inició la diversificación de los desarrollos socio-económicos. Junto con una gama de modos de vida y expresiones culturales, se manifestó también distintas formaciones económico-sociales, donde la propiedad se presentó de modo "colectivo", sin pertenencia establecida institucionalmente sobre los objetos naturales de trabajo, sólo posesión territorial, y por tanto sus espacios naturales de refugio eran multifuncionales; pero para cuando se instituye la capacidad social de disponer sobre los medios naturales de producción y más aún, cuando se da paso a sociedades clasistas, donde las relaciones de propiedad se complejizan, dicha complejidad también se reflejó en la forma del asentamiento y por ende en sus espacios de refugio; lo cual permite ahondar de modo específico en la definición de la unidad residencial, pues debe anotarse que si se toma en cuenta el material constructivo (incluyendo los acabados), la técnica constructiva y el diseño (forma y función) empleado en su configuración, entonces podrá distinguirse, de modo general, dos variantes en la agrupación de la unidades residenciales: las de alto estatus y aquellas de bajo estatus; las que a su vez pueden diferenciarse, de ser posible, según las clases sociales a las que pertenecieron.

Finalmente, al margen de los considerandos, es necesario, precisar que un derrotero para alcanzar el nivel explicativo del desarrollo histórico de una sociedad determinada, es el estudio espacial (no sólo disposición, sino también el análisis contextual) de las unidades residenciales, lo cual permitirá su articulación con los otros componentes del asentamiento y sus prácticas internas sociales, políticas, económicas e incluso, ideológicas; para luego contrastar dicha información con la de otras comunidades coetáneas ${ }^{14}$.

\section{Agradecimientos}

Agradezco al colega y amigo Daniel Cáceda Guillén por el intercambio de ideas y conceptos que surgieron en el marco de distintas conversaciones referentes a las limitaciones que suelen darse durante el proceso de investigación arqueológica.

14. Todo lo contrario a la justificación de quienes prefieren partir desde el estudio de lo "espectacular" que resulta siendo la arquitectura pública monumental, en un sentido erróneo por querer comprender a una sociedad determinada, especulando desde una superestructura en proceso de identificación, sin llegar a establecer la articulación con las otras instancias materiales de la referida sociedad. 


\section{BiBLIOGRAFÍA}

ÁLVEZ MORA, César A.

1992 "Un estudio de campamentos paijanenses en la Quebrada Cuculicote, valle de Chicama": 21-43. En: Estudios de Arqueología Peruana (418 p.). Duccio Bonavia (editor). FOMCIENCIAS. Lima.

BENFER Jr., Robert A.

1999 "Proyecto de excavaciones en Paloma, valle de Chilca, Perú": 213-237. En: El Período Arcaico en el Perú: Hacia una definición de los orígenes. Peter Kaulicke, editor. Boletín de Arqueología. P.U.C.P. $\mathrm{N}^{\circ}$ 3. Fondo Editorial. Lima.

BRICEÑO Rosario, Jesús G. y Mario Millones

1999 "Los restos humanos más tempranos del Norte del Perú: Balance y proyecciones": 55-67. En: El Período Arcaico en el Perú: Hacia una definición de los orígenes. Peter Kaulicke, editor. Boletín de Arqueología. P.U.C.P. N³. Fondo Editorial. Lima.

CANZIANI A., José

2009 Ciudad y territorio en los Andes. Contribuciones a la historia del urbanismo prehispánico. (549 p.). Fondo Editorial. Pontificia Universidad Católica del Perú. Lima.

CARMICHAEL, Patrick H.

1994 “Cerámica Nasca: Producción y contexto social”: 229-247. En: Tecnología y organización de la producción cerámica prehispánica en los Andes (519p.). Izumi Shimada (Editor). Pontificia Universidad Católica del Perú. Fondo Editorial. Lima.

CHAUCHAT, Claude

2006 Prehistoria de la Costa Norte del Perú. El Paijanense de Cupisnique. (414 p). Instituto Francés de Estudios Andinos. Patronato Huacas del valle de Moche. Lima.

CIEZA DE LEÓN, Pedro

1973 (1548 - 1550) La Crónica del Perú (262 p). Biblioteca Peruana. Lima.

DILLEHAY, Tom D.

2006 "Organización y espacios sociopúblicos incipientes: Tres casos de los Andes": 13-36. En: Boletín de Arqueología PUCP. N 10. Procesos y Expresiones de Poder, Identidad y Orden Tempranos en Sudamérica (Primera parte). Lima.

ESPINOZA S., Waldemar

1997 Los Incas. Economía, Sociedad y Estado en la Era del Tahuantinsuyo (510 p.). Amaru Editores. Lima.

FUNG PINEDA, Rosa

1999 "El proceso de Neolitización en los Andes Tropicales": 141-196. En: Historia de América Andina. Las Sociedades Aborígenes. Volumen I (605 p.). L. G. Lumbreras (Editor). Universidad Andina Simón Bolivar. Quito. 
GASPARINI, Graziano y Luise Margolies

1977 Arquitectura Inka. (357 p.). Centro de Investigaciones Históricas y Estéticas, Facultad de Arquitectura y Urbanismo, Universidad Central de Venezuela. Caracas.

GOLDHAUSEN, Marco; Carlos Viviano; Julio Abanto; Pedro Espinoza y Ronald Loli

2006 "La ocupación precerámica en la Quebrada Orcón-Pacaybamba, valle medio de Chancay, Lima”. En: Boletín de Arqueología PUCP. № 10: 137-166. Procesos y Expresiones de Poder, Identidad y Orden Tempranos en Sudamérica (Primera parte). Lima.

INSTITUTO NACIONAL DE CULTURA

2000 Plan Maestro para la conservación y el manejo del Complejo Arqueológico Chanchan. INC. Lima.

ISLA C., Johny

2010 “Perspectivas sobre el proceso cultural en los valles de Palpa, costa sur del Perú": 15-52. En: Arqueología y Desarrollo, Experiencias y Posibilidades en el Perú. Editor Luis Valle Álvarez - Ediciones SIAN. Trujillo.

LARCO HOYLE, Rafael

1948 “Cronología arqueológica del norte del Perú. Biblioteca del Museo de Arqueología Rafael Larco Herrera, Hacienda Chiclín”. Sociedad Geográfica Americana. Buenos Aires. [Reimpreso en: Arqueológicas N² 25, Lima, 2001].

LAVALLÉE, Daniéle

1995 Telarmachay, cazadores y pastores prehistóricos de los Andes. Traducido al castellano por D. Pozzi-Escot. Instituto Francés de Estudios Andinos. Lima.

LEONI, Juan B.

2007 "La ocupación Wari de Ñawinpukyo: trazado espacial, arquitectura y organización social en una comunidad ayacuchana del Horizonte Medio": 131-154. En: Arqueología y Sociedad, $\mathrm{N}^{\circ}$ 18. Museo de Arqueología y Antropología, Centro Cultural de San Marcos, Universidad Nacional Mayor de San Marcos. Lima.

LÉVI-STRAUSS, Claude

1977 Antropología estructural. Editorial Universitaria de Buenos Aires, Eudeba. Buenos Aires.

LUMBRERAS, Luis G.

1981 Arqueología de la América Andina (277 p.). Carlos Milla Batres (Editor). Editorial Milla Batres. Lima.

MAKOWSKI, Krzysztof

2006 "La arquitectura pública del Periodo Precerámico Tardío y el reto conceptual del urbanismo andino": 167-199. En: Boletín de Arqueología PUCP. N 10. Procesos y Expresiones de Poder, Identidad y Orden Tempranos en Sudamérica (Primera parte). Lima.

MANZANILLA, Linda

1986 “Introducción" 9-18, en: Unidades habitacionales mesoamericanas y sus áreas de actividad. L. Manzanilla (Editora). (Arqueología, Serie Antropológica 76), Instituto de Investigaciones Antropológicas. Universidad Nacional Autónoma de México. México D. F. 
MAZOYER, Marcel y Laurence ROUDART

1997 Histoire des agricultures du monde. Du néolithique à la crise contemporaine. (545p.) Edición du Seuil.

NOEL E., Arturo

2009 "La unidad doméstica y la residencia del pasado: consideraciones teóricas y metodológicas desde los Andes Centrales". En: Revista de Ciencias Sociales Unay Rvna, $\mathrm{N}^{\circ}$ 8. Instituto Cultural RVNA, 67-97. Lima.

PEASE G., Franklin; Craig MORRIS; Julián I. SANTILLANA; Ramiro MATOS; Paloma CARCEDO DE MUFARECH; Luisa VETTER PARODI; Carmen ARELLANO; Vuka ROUSSAKIS y Lucy SALAZAR

1999 Los Incas. Arte y Símbolos. (328 p.). Colección Familiar Arte y Tesoros del Perú. Banco de Crédito del Perú. Lima.

PONTE, Víctor

2007 "Pastores de puna del periodo Horizonte Medio en el Callejón de Huaylas, Perú": 95-130. En: Arqueología y Sociedad, $\mathrm{N}^{\circ} 18$. Museo de Arqueología y Antropología, Centro Cultural de San Marcos, Universidad Nacional Mayor de San Marcos. Lima.

SHADY, Ruth

2005 Caral. La ciudad del fuego sagrado (259 p.). Centura Sab, Lima.

2006 "La civilización Caral: Sistema social y manejo del territorio y sus recursos. Su trascendencia en el proceso cultural andino": 59-89. En: Boletín de Arqueología PUCP. № 10. Procesos y Expresiones de Poder, Identidad y Orden Tempranos en Sudamérica (Primera parte). Fondo Editorial. Pontificia Universidad Católica del Perú. Lima.

SHIMADA, Izumi

1994 "La producción de cerámica en Mórrope, Perú: Productividad, especialización y espacio vistos como recursos". En: Tecnología y organización de la producción cerámica prehispánica en los Andes (519 p.). Izumi Shimada (Editor). Pontificia Universidad Católica del Perú. Fondo Editorial, 295-319, Lima.

TELLO, Julio C. y Toribio MEJIA XESSPE

1979 Paracas. Segunda parte: Cavernas y Necrópolis. Universidad Nacional Mayor de San Marcos. Lima.

TELLO, Ricardo

2008 "Las tumbas del Conjunto Arquitectónico 35 - 2002, Huacas del Sol y de la Luna: cambios en la arquitectura y función": 185-208. En: Investigaciones en la Huaca de la Luna 2002 (358 p.). S. Uceda, E. Mujica y R. Morales (editores). Proyecto Arqueológico Huacas del Sol y de la Luna. Patronato Huacas del Valle de Moche. Facultad de Ciencias Sociales, Universidad Nacional de Trujillo. Trujillo. 
TELLO, Ricardo; Francisco SEOANE; Krisna SMITH; Jorge MENESES, Alfonso BARRIGA y Jessenia PALOMINO

2008 "El Conjunto Arquitectónico 35 de las Huacas del Sol y de la Luna: cambios en la arquitectura y función”: 93-142. En: Investigaciones en la Huaca de la Luna 2002 (358 p.). S. Uceda, E. Mujica y R. Morales (editores). Proyecto Arqueológico Huacas del Sol y de la Luna. Patronato Huacas del Valle de Moche. Facultad de Ciencias Sociales, Universidad Nacional de Trujillo. Trujillo.

VILLACORTA O., Luis Felipe

2004 "Los palacios en la Costa Central durante los periodos tardíos: de Pachacamac al Inca": 539-570. En: Arqueología de la Costa Central del Perú en los Periodos Tardíos (891 p.). Editado por Peter Eeckhout. Bulletin de l'Institut Français d’Études Andines. Tome 33, Nº 3. Lima.

WURSTER, Wolfgang W.

1997 “Desarrollo del urbanismo prehispánico en el valle de Topará, costa sur del Perú”: 13-27. En: Archaeologica Peruana 2. Arquitectura y Civilización en los Andes Prehispánicos. Editores: Elizabeth Bonnier y Henning Bishof. Sociedad Arqueológica Peruano - Alemana. Reiss - Museum Mannheim. Mannheim. 
